\title{
TERRITÓRIO INDÍGENA DO MASSACARÁ: URBANIDADE RURAL, RURALIDADE URBANA
}

\section{The indigenous territory of Massacará: urban rurality, rural urbanity}

\author{
Alfons Heinrich Altmicks \\ (PPGEDUC-UNEB). \\ Informações do artigo \\ Recebido em 22/08/2020 \\ Aceito em 04/09/2020 \\ doi>: https://doi.org/10.25247/2447-861X.2020.n251.p546-566

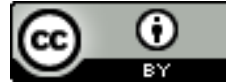 \\ Esta obra está licenciada com uma Licença Creative Commons \\ Atribuição 4.0 Internacional. \\ Como ser citado (modelo ABNT) \\ ALTMICKS, Alfons Heinrich. Território indígena do \\ Massacará: urbanidade rural, ruralidade urbana. \\ Cadernos do CEAS: Revista Crítica de Humanidades. \\ Salvador/Recife, v. 45, n. 251, p. 546-566, set./dez., \\ 2020. DOI: https://doi.org/10.25247/2447- \\ 861X.2020.n251.p546-566
}

\begin{abstract}
Resumo
Este artigo tem o escopo de evidenciar as relações entre territorialidade e identidade étnica, no Território Indígena do Massacará, pertencente à etnia Kaimbé, partindo da dicotomia entre os elementos de urbanidade rural e de ruralidade urbana, elaborados pela população local. Contando com cinco séculos de contato com a sociedade de entorno, os Kaimbé tiveram que aprender a lidar com modelos culturais e institucionais, que não os seus próprios. Desse aprendizado, brotou uma maneira, muito particular, de relacionamento com o universo nãoindígena. Este estudo traduz um esforço teórico, cujo resultado deverá subsidiar uma investigação etnográfica mais ampla, sobre a importância do território para a consubstanciação da identidade indígena Kaimbé. Outrossim, constitui uma pesquisa de prospecção, fundamentada na experiência dos autores, na localidade, bem como na literatura contemporânea disponível sobre o tema.
\end{abstract}

Palavras-Chave: Território. Territorialidade. Identidade étnica. Etnodesenvolvimento. Indígenas Kaimbé.

\section{Abstract}

This paper aims to show the relationship between territoriality and ethnic identity in the Indigenous Territory of Massacará, formed by the Kaimbé ethny, through the dichotomy between the rural urbanity and the urban rurality, created by locals. Throughout five years of relationship with the society around them, the Kaimbe have had to deal with different cultural and institutional models. From this learning relationship, a very peculiar way of relating to the non-indigenous universe was born. This study is a theoretical effort, whose result shall base a wider ethnographic investigation on the role of the territory to the consubstantiation of the Kaimbé's indigenous identity. Furthermore, it is a prospective research, based on the author's local experience, as well as in the available contemporary literature on the subject.

Keywords: Territory. Territoriality. Ethic identity. Etnodevelopment. Kaimbé's indians. 


\section{Introdução}

Não raramente, a heterogenia cultural indígena provoca equívocos sobre o processo de integração das populações indígenas à sociedade de entorno ${ }^{1}$, porquanto há uma miríade de nuances culturais, a ser realçada, quando se toma, para análise, o tema da cultura indígena e suas relações com a construção da identidade brasileira. Com efeito, cada povo indígena é constituído de idiossincrasias e especificidades, que o tornam único, eleito na beleza e na riqueza do seu manancial cultural. No Brasil, conquanto o desconhecimento sobre o universo indígena seja acintoso e sistemático, constituindo um projeto de negação de uma matriz étnica (CANTON, 2018), a diversidade de culturas indígenas termina posta sob a égide de um indianismo genérico, no qual é ressaltado o estereótipo do silvícola, seminu, ingênuo, ignorante.

Esse reducionismo é subscrito, inclusive, às concepções sobre a maneira como as populações indígenas se apropriam das instituições não-indígenas, ressignificando-as. A despeito de, flagrantemente, mal acomodadas às dinâmicas da sociedade de entorno, as etnias indígenas se relacionam com instituições não-indígenas, como a escola, a universidade, o modelo de família, a estrutura de saúde pública etc. Obviamente, esse convívio requer o desenvolvimento de estratégias de adaptação, em relação a essas instituições. Aos olhos dos não-indígenas, essas estratégias ratificam a imagem reducionista do indígena² como um ser inferior (MEADER, 1976; OLIVEIRA, 1998;1999; 2011; BATISTA, 2011; (ANTON, 2018).

Todas estas acusações não passam despercebidas pela população Kaimbé, sobretudo, porquanto padeçam, igualmente, das acusações supracitadas, velada ou abertamente (REESINK, 1983; 1984; 2017; REESINK, MCCALLUM; RESTREPO, 2017). Vivendo no "Sertão do Massacará", município de Euclides da Cunha, Bahia, os Kaimbé convivem com conflitos e desconfianças sobre o seu estatuto de indianeidade ${ }^{3}$, que

\footnotetext{
1 "Sociedade do entorno", expressão cunhada pelos antropólogos brasileiros ao se referirem aos agrupamentos urbanos e rurais que circundam as aldeias ou os territórios indígenas (LINDOSO, 2008).

2 Para este estudo, sob a orientação de Canton (2018), optou-se pelo uso do vocábulo "Indígena", qualificativo, no lugar de "Índio", denotador de naturalidade étnica.

3 Por "indianeidade", entende-se a assunção de uma cosmovisão legitimamente indígena, tradutora da sua identidade étnica, do seu pertencimento e da sua territorialização. O termo, assim, ganha similaridade, por exemplo, com o termo "negritude", que denota, no Brasil, a identidade cultural comum aos descendentes dos povos colonizadores de matriz africana (GONÇALVES, 2015).
} 
perduram até os dias atuais e são manifestados, abertamente, em termos pejorativos, com os quais, muitos não-indígenas da Região se referem às suas comunidades: "Índios da cidade", "Índios arrocheiros" 4 , "caboclos de araque"5 etc.

Os questionamentos sobre a legitimidade étnica dos Kaimbé se bipartem em dois eixos: críticas à variada condição fenotípica da sua população, uma vez que é possível encontrar uma multiplicidade de tezes, traços e compleições físicas; e críticas aos seus hábitos de consumo, sobretudo, no que se refere ao tipo de residência em que habitam, ao seu vestuário e uso de recursos tecnológicos, por parte da população Kaimbé, a exemplo de motos, celulares e antenas parabólicas (REESINK, MCCALLUM; RESTREPO, 2017)

Delineia-se, então, o tema que norteia este estudo, qual seja, a maneira como os Kaimbé ressignificam instituições, entes culturais e produtos da sociedade de entorno, tornando-os veículos para a assunção e para a divulgação da sua identidade étnica. À guisa de objetivo, este estudo procura analisar até que ponto os Kaimbé utilizam esses elementos da sociedade de entorno para afirmar a sua própria identidade étnica, trazendo, para o seu cotidiano, características de pertencimento e territorialidade, reveladores da sua indianeidade. O percurso metodológico, aqui desenvolvido, foi ancorado, basicamente, na experiência dos autores, atuantes no Território Indígena do Massacará, e na consulta bibliográfica, o que lhe confere o caráter compilatório de pesquisa de revisão de literatura.

\section{Territorialidade Kaimbé}

Moquay $(1998 ; 2001)$ advoga um conceito de território indissociado da ideia de comunidade e luta por direitos. Nesse sentido, o caso dos Kaimbé é emblemático: as lutas pela demarcação das suas terras remontam à década de 1980, quando houve uma mobilização das lideranças indígenas Kaimbé e Kiriri em torno da demarcação das terras que, antes, pertenciam à fazenda Mirandela. A retomada foi violenta e houve mortes, até que, enfim, o Governo Federal interveio e passou a regularizar a situação fundiária das duas etnias. De lá até os dias atuais, muitos avanços ocorreram, em relação ao reconhecimento de terras

4 Referência ao "Arrocha", gênero musical popular, muito apreciado na região.

5 Segundo Sousa (2018), a expressão "de araque", cujo significado é "de mentira, falso", tem origem na bebida árabe, arak, trazida ao Brasil pelos imigrantes árabes. Segundo o autor, os brasileiros, afirmavam que o arak era uma "cachaça falsa". Dai, "de araque" se tornar sinônimo de "falso". 
indígenas do Massacará, embora o direito à terra só fosse conquistado através da organização dos indígenas e da sua insistência no pleito.

Os conflitos pela posse e propriedade das terras do Massacará foram tão intensos, que os Kaimbé foram instados a migrar para lotes alhures, sob a anuência do Estado, mas eles se recusaram, sob a alegação de que havia uma poderosa relação de pertencimento entre Kaimbé e Massacará, de maneira que retirá-los do Massacará implicaria em exilá-los da sua própria condição indígena.

Sobre este aspecto, Faria (2003) realiza a seguinte leitura:

[...] a terra, na visão do Estado, é um espaço homogêneo, meio de produção onde estão distribuídos recursos naturais. Na concepção indígena, terra é um mosaico de recursos materiais, morais e espirituais; seu território, além de conter dimensões sociopolíticas, também cotem uma ampla dimensão cosmológica [...]. A importância do território está no seu significado, pois as nações indígenas [...] constroem a sua identidade por meio da relação mitológica que mantêm com o território [...]. Trata-se de uma identidade criada em relação a uma geografia determinada. (FARIA, 2003, p. 4).

É importante notar que o conceito de território não se subscreve a algo estático; pelo contrário, é profundamente devedor das ideias de movimento social, transformação produtiva, imaginário, cosmovisão, pertencimento. Segundo Carvalho (1997):

[...] o território indígena não se caracteriza fundamentalmente por estatuto de 'produtividade'. Os fatores que consideram essenciais para integrá-lo decorrem de coordenadas culturais particulares, oriundas das relações sociais de parentesco e organização social (CARVALHO, 1997, p. 15).

Toledo, Giatti e Pelicioni (2008) completam:

[...] a noção de território adquire [...] claramente valores sociopolíticos, e acreditase que, dentre outros aspectos, são as ações sociais de mobilização que garantem o contínuo e permanente processo de construção de um território, pois sem essa ação social o território torna-se apenas um lugar. [...] A noção de território amplia-se podendo contribuir para a compreensão das práticas sociais, pois é por meio das relações com o outro, do confronto com o outro, que um território se constitui na historicidade das relações sociais estabelecidas. [...]. (TOLEDO; GIATTI; PELICIONI, 2008, p. 179). 
Perante esta concepção de território, que supõe dialogia, dicotomia e prática social, é necessário identificar as situações de conflito, presentes à Serra do Massacará. O mais evidente conflito ocorre entre indígenas e não-indígenas ${ }^{6}$, especialmente, por conta do nãoreconhecimento da indianeidade Kaimbé. O fato de que os Kaimbé tenham incorporado características de urbanidade, ao seu cotidiano, só agravou as desconfianças sobre a sua origem étnica. Com frequência, os Kaimbé são instados a comprovar a sua indianeidade, perante a sociedade do entorno.

No cerne desta análise, a identidade e a territorialidade são indissociáveis, porquanto traduzam pertencimento. O conceito de pertencimento, aqui adotado, traduz a crença que um grupo, portador de identidade étnica, sustenta sobre a sua origem, histórica, genealógica, espiritual ou cultural, constituindo, desde a sua cosmovisão até o seu ethos. O pertencimento também contempla a importância do território geográfico para a assunção da sua identidade étnica. Desta forma, o pertencimento Kaimbé legitima a origem comum dos indivíduos Kaimbé, dentro do seu manancial sociocultural, mas, também, matiza a sua territorialidade (APPADURAI, 2006).

O pertencimento de um povo, segundo Appadurai (2006), revela as relações entre a sua cultura e a sua identidade étnica, em relação ao seu território. O processo de desterritorialização, dessa maneira, implica, naturalmente, o esfacelamento cultural desse povo e o consequente prejuízo para a sua identidade étnica, tal como ocorreu com os Kaimbé, entre os séculos XIX e XX. Desapropriados pelos conflitos fundiários da região, os Kaimbé perderam, a um só tempo, a posse e a propriedade do seu território e da sua identidade, a ponto de terem sido considerados extintos.

Desta forma, os Kaimbé recusaram a migração, proposta pelo Estado, na forma da doação de lotes distantes, e optaram pela permanência e pelo conflito, culminando com a demarcação do Território Indígena do Massacará (BRASIL, MPF, 2013). Vencida essa etapa, outros desafios se lhes apresentaram, especialmente, em relação à produção da sua sobrevivência. Conquanto as políticas para o desenvolvimento econômico, propostas pelo

\footnotetext{
6 A este conflito, outros se seguem, como o choque entre as gerações mais tradicionais e os índios mais novos, ou entre os Kaimbé católicos e os neopentecostais, homens e mulheres Kaimbé etc. No entanto, para os interesses deste artigo, não são relevantes e, portanto, serão suprimidos da análise.
} 
Estado para a população Kaimbé, não trouxessem autonomia (SOUZA, 1996b), eles passaram a pleitear as bases do seu próprio etnodesenvolvimento.

\section{Etnodesenvolvimento indígena Kaimbé}

Gründewald (2003) destaca que há certa promiscuidade entre os conceitos de etnodesenvolvimento e de desenvolvimento sustentável, aplicado às comunidades etnicamente diferenciadas. O desenvolvimento sustentável, aplicado às comunidades etnicamente diferenciadas, apenas favorece às questões econômicas, de uso racional e sustentável dos seus recursos naturais, não colaborando, necessariamente, para o seu fortalecimento étnico, cultural e político, condição para a ocorrência do etnodesenvolvimento7.

No entanto, o mesmo (GRÜNDEWALD, 2003) não entende que a concomitância, entre o etnodesenvolvimento e o desenvolvimento sustentável, aplicado às comunidades etnicamente diferenciadas, constitui um problema, ou que possam ser, de alguma forma, excludentes entre si. Ele apenas adverte para o perigo do reducionismo conceitual, pois, ao categorizar o etnodesenvolvimento como sinônimo de desenvolvimento sustentável, aplicado às comunidades etnicamente diferenciadas, deixa-se escapar a abrangência do termo, sobretudo, no que diz respeito à sua capacidade de potencializar as identidades étnicas.

O conceito de desenvolvimento sustentável surgiu, na década de 1960, no contexto das discussões sobre desenvolvimento social e desenvolvimento com preservação ambiental, especialmente, voltadas para o crescimento econômico e social dos Terceiro e Quarto

\footnotetext{
7 A despeito do que pensam os autores (STAVENHAGEN, 1984; GRÜNDEWALD, 2003; AZANHA, 2002), no Brasil, é necessário relativizar os conceitos de "sustentabilidade" e de "desenvolvimento sustentável", pois partem de ideais, que demandam e implicam um conjunto de benefícios, integrados, de forma holística, na sociedade, o que não ocorre no País. Com efeito, pode-se até entender que haja iniciativas pontuais de desenvolvimento sustentável, em muitas regiões brasileiras, mas, ao mesmo tempo, é preciso compreender que essas iniciativas, fatalmente, convivem com outras propostas de atividades econômicas, que são convencionais e, em nada, se relacionam com a sustentabilidade. Assim, ainda que muito se discuta a "sustentabilidade" e o "desenvolvimento sustentável, no Brasil, é necessário colocar esses conceitos em perspectiva, pois, aqui, não possuem os mesmos sentidos que, por exemplo, podem ter em países europeus desenvolvidos, como a Alemanha, a Dinamarca ou a Finlândia.
} 
Mundos $^{8}$. A tese vigente era a de que esses modelos alternativos de desenvolvimento possibilitariam o gradual fortalecimento econômico e político dos países dominados pelo Primeiro Mundo, provocando, posteriormente, a sua emancipação. Esses modelos alternativos de desenvolvimento tinham, como características, a ênfase nos objetivos sociais e ambientais. De acordo com Nash (1996), a ideia de sustentabilidade ambiental terminou por catalisar todas estas tendências alternativas de desenvolvimento, e a expressão "desenvolvimento sustentável" foi designada para "[...] se referir a um interesse em conservar a natureza" (NASH, 1996, p. 122).

Para Gründewald (2003), há uma conexão profunda entre a ideia de sustentabilidade e as questões ambientais, de maneira que não é surpreendente que a confluência de todos os modelos alternativos, propostos como antagonistas naturais ao modelo predatório do conceito de desenvolvimento, engendrado pelo Capitalismo, tenha ocorrido por via da "consciência ambiental". De fato, a manutenção de um meio ambiente propício à vida humana é condição basilar, tanto para a produção quanto para o bem-estar das populações. Por isso, talvez, o "Relatório Brundtland"9 (ONU, 1988) conceitue o desenvolvimento sustentável como aquele que atende às necessidades do presente, sem comprometer o suprimento das necessidades das futuras gerações.

Embora os conceitos de sustentabilidade e de desenvolvimento sustentável componham, de certa maneira, o lastro daquilo que se entende por etnodesenvolvimento, certamente, não o determinam, nem o limitam. Etnodesenvolvimento ultrapassa o simples desenvolvimento sustentável aplicado aos territórios das comunidades indígenas ${ }^{10}$. Gründewald (2003) advoga a ideia de que Etnodesenvolvimento seja:

\footnotetext{
${ }^{8}$ Termos utilizados, à época, para categorizar e classificar as economias, de acordo com os seus potenciais de crescimento econômico e de manutenção de condições produtivas.

9 Elaborado pela Comissão Mundial sobre o Meio Ambiente e o Desenvolvimento, o "Relatório Brundtland compõe uma crítica ao modelo predatório de desenvolvimento, adotado pelos países industrializados e imitado pelas nações em processo de desenvolvimento (NASH, 1996).

${ }^{10}$ Evidentemente, assim como os conceitos de "sustentabilidade" e de "desenvolvimento sustentável", supracitados, o conceito de "etnodesenvolvimento", também, deve ser colocado em perspectiva. Etnodesenvolvimento constitui uma ideia aceitável, se circunscrita ao microcosmo étnico, surgida da autodeterminação indígena. No Brasil, conquanto as populações indígenas sejam tuteladas pela FUNAl, a sua autonomia e a sua autodeterminação estão comprometidas pela pouca efetividade das ações engendradas pelo órgão.
} 
[...] o desenvolvimento sustentável de uma comunidade étnica quando aliado ao revigoramento do seu patrimônio cultural e conseqüente fortalecimento da sua identidade étnica, isto é, à sua etnicidade - sustentando a etnia, a determinação étnica. (GRÜNDEWALD, 2003, p. 50).

Desta forma, entende-se que os diferentes espaços do Território Indígena do Massacará podem apresentar propostas de desenvolvimento em termos capitalistas, sustentáveis ou étnicos, afinal, não se pode esquecer que os Kaimbé estão cercados por um - e inseridos num - modelo produtivo que privilegia o Capital. Com efeito, há uma concomitância destas propostas de desenvolvimento das povoações do Massacará. Em certos espaços, as atividades produtivas priorizam as relações capitalistas; noutros, incentivadas pelo discurso da sustentabilidade, as atividades vão de encontro ao modelo de desenvolvimento sustentável; em alguns, ainda, são desenvolvidas atividades que fortalecem a identidade étnica, configurando etnodesenvolvimento.

Diante dessa convivência de modelos, Azanha (2002, p. 31) acredita que o entrave ao etnodesenvolvimento indígena fosse a necessidade de "[...] se reproduzirem como sociedades etnicamente diferenciadas e lidar, ao mesmo tempo, com condições materiais de existência cada vez mais adversas e multifacetadas". Em relação aos Kaimbé, a essas dificuldades são, ainda, as desconfianças sobre a legitimidade da sua própria identidade indígena.

Stavenhagen (1984) infere que o etnodesenvolvimento traduz a autonomia e a autodeterminação das populações indígenas, no sentido do abandono dos modelos desenvolvimentistas do Capitalismo, francamente identificados com o progressismo, e em prol da assunção de uma forma identitária de desenvolvimento, que contemple o diferencial étnico e cultural das populações indígenas. Na sua definição:

[...] o etnodesenvolvimento significa que uma etnia, autóctone, tribal ou outra, detém o controle sobre suas próprias terras, seus recursos, sua organização social e sua cultura, e é livre para negociar com o Estado o estabelecimento de relações segundo seus interesses" (STAVENHAGEN, 1984, p. 57).

Para o mesmo (STAVENHAGEN, 1984, P 58-59), o Etnodesenvolvimento é construído sobre alguns princípios fundantes, quais sejam: a resolução dos problemas e o suprimento das necessidades individualizadas das pessoas e dos grupos pertencentes à comunidade, em detrimento da priorização das questões econômicas exógenas; a utilização dos saberes e das 
tradições do grupo para dar soluções aos problemas enfrentados coletivamente; a busca do equilíbrio no uso do meio ambiente como manancial de produção da sobrevivência do grupo; a construção própria das soluções aos problemas do grupo; e a coletivização das decisões do grupo, a despeito da existência de lideranças tradicionais.

O etnodesenvolvimento Kaimbé demanda, assim, o cumprimento desses princípios fundantes, dos quais, naturalmente, brotaria a sua autonomia (SOUZA, 1996b). Numa relação dialética, é possível intuir que, tal como a identidade Kaimbé advém do conflito entre o ser Kaimbé e o não ser Kaimbé, o etnodesenvolvimento no Território Indígena do Massacará surgiria do confronto entre o se desenvolver Kaimbé e não se desenvolver Kaimbé, trazendo à tona as questões da urbanidade rural Kaimbé.

\section{Urbanidade rural kaimbé}

As transformações, trazidas pelo contato entre os Kaimbé e sociedade do seu entorno, confluem para a transposição de práticas urbanas para os ambientes rurais, processo ao qual Moquay $(1998 ; 2001)$ denominou "urbanidade rural". Note-se que não se trata da incorporação do espaço rural pela cidade, muito menos da sobreposição da vida urbana ao ambiente rural. Muito pelo contrário, urbanidade rural representa a apropriação e a ressignificação do know-how próprio da cidade pelo ambiente rural, de maneira a preservarIhe a autonomia e a tradição.

Na Serra do Massacará, território Kaimbé, certas características urbanas, como a circulação de motos, a onipresença de aparelhos celulares, a oferta de emprego, o acesso a produtos industrializados, foram assimiladas, mas ressignificadas, para atender aos costumes da identidade étnica e territorial Kaimbé, cuja cosmovisão é legitimada pelos conhecimentos tradicionais, que permanecem como pertinentes e incontestes. Essa cosmovisão mantem uma identidade rural, mesmo diante dos incrementos do mundo urbano.

Segundo Moquay (1998; 2001), a urbanidade rural traduz um processo de adaptação das tradições às novas realidades impostas pelo contato com o universo urbano. No núcleo do Massacará, por exemplo, técnicos da área de saúde ganharam valor de consultores sobre as questões da comunidade, sobretudo, porque eles podem barganhar melhorias para a população indígena. Apesar de ocorrerem essas adaptações e a efetivação de lideranças, nem 
sempre tão tradicionais, o bem do grupo é sempre almejado. Os Kaimbé procuram reforçar a identidade étnica e territorial, buscando obter o poder de decidir o destino das suas comunidades.

Sobre as questões que envolvem elementos de urbanidade e ruralidade no cotidiano dos Kaimbé, é interessante analisar as ideias de Carneiro (2003). Para a autora, a Sociologia Rural tradicional matizou a ideia de sociedade moderna, dicotomizada pela presença de ambientes rurais e urbanos, realidades mais ou menos conformadas, porém, entre si, marcadas por franca oposição. Como apoio dessa dicotomia, foram eleitos, basicamente, os critérios da experiência empírica ${ }^{11}$ e das expressões produtivas de ambos os espaços. Assim, pouco a pouco, os conceitos de "rural" e "urbano" foram se confundindo com os conceitos de "agrícola" e "industrial". Essa confusão conceitual pautou a metodologia tradicional da Sociologia Rural até o ponto em que não mais pôde se sustentar, diante da riqueza e da pluralidade de manifestações socioprodutivas das sociedades rurais e urbanas contemporâneas.

Num primeiro momento, seguindo os ditames do evolucionismo social, herdado do positivismo comteano, a Sociologia Rural tradicional tendeu a valorizar o espaço urbano, representante do desenvolvimento, em detrimento do ambiente rural, marcado pelo anacronismo e pela inércia. Nesse sentido, o estudo do ambiente rural passou a ser instrumental, focando a evolução técnica e tecnológica da produção agrícola, como critério de desenvolvimento social e econômico do espaço rural, cuja inspiração seria o ambiente urbano (CARNEIRO, 2003).

A extensão natural da dicotomia, e da relação mutuamente excludente, entre o urbano e o rural, no que se refere aos povos etnicamente diferenciados, foi a suposta oposição entre os modelos civilizatórios citadino e indígena, em termos equivalentes à primeira relação dicotômica, quais sejam, a valorização do citadino em detrimento do indígena ${ }^{12}$. Por esse motivo, enquanto preponderou a interpretação da Sociologia Rural tradicional, no Brasil, as políticas públicas, formuladas pelo Estado, voltadas aos segmentos rurais, priorizaram o desenvolvimento da agricultura de larga escala e do hoje chamado

\footnotetext{
${ }^{11}$ Ou sejam a diferença entre os espaços rural e urbano.

${ }^{12}$ Evidentemente, tal oposição é extensiva a quaisquer outros povos etnicamente diferenciados.
} 
"agronegócio". Em contrapartida, outras formas produtivas vigentes, no meio rural, inclusive aquelas que brotam das sociedades indígenas, foram simplesmente ignoradas e, praticamente, não compuseram o rol das políticas públicas dirigidas ao setor (FORNO; VERDUM; KUBO, 2010).

De acordo com Souza (1996a), os Kaimbé, à essa época ${ }^{13}$, encontravam-se desarticulados e espalhados por diversas localidades, na região, imersos na formas locais de campesinato, tendo sido, até mesmo, considerados como uma etnia extinta. No momento em que ensaiaram pleitear garantias para a sua indianeidade, foram rechaçados, sob o argumento, dentre outros, de que não lograriam desenvolver uma atividade agrícola consistente, ainda que legitimados como indígenas. Com efeito, não havia instrumentos legais que subsidiassem o modelo produtivo agrário, típico da tradição Kaimbé.

A ênfase desenvolvimentista provocou, no ambiente rural, uma instrumentalização técnica, promovida por políticas públicas, munidas dessa concepção evolucionista. Como consequência, a produção agrícola se expandiu em nível industrial, conformando "desertos verdes" na paisagem rural ${ }^{14}$. A percepção de que, por um lado, a presença da agricultura em escala industrial não aliviava o problema da fome na sociedade e de que, por outro lado, acentuava os paradoxos ecológicos e socioambientais, fez com que o modelo evolucionista fosse questionado, abrindo espaço para interpretações de natureza mais idealistahumanistas, do que advém o ambientalismo (CARNEIRO, 2003).

A partir da década de 1980, o foco da discussão, então, deslocou-se para a ênfase no espaço rural, sem perder de vista a dicotomia rural x urbano. Engendrada, sobretudo, pelos antropólogos, esta interpretação colocou o ambiente rural como ideal de qualidade de vida. Note-se que se trata de uma ruralidade idílica, imaginária. A vida no campo representaria a simplicidade, a saúde, o afastamento das vicissitudes da sociedade urbana, caracterizada pelo consumo, pela ausência de valores humanos, pela violência, pelo ritmo vertiginoso. Nessa corrente de pensamento, o espaço urbano representava uma ameaça à vida no ambiente rural (CARNEIRO, 2003).

\footnotetext{
${ }^{13}$ Entre os anos de 1940 e 1980.

${ }^{14}$ Os ambientalistas descrevem os desertos verdes como áreas de cobertura agrícola, ou de vegetação nãonativa, em larga escala, cujo manejo impede a existência da flora e da fauna nativas (FORNO; VERDUM; KUBO, 2010).
} 
Segundo Carneiro (2003), para os pensadores dessa corrente, no lugar das características sociogeográficas, empiricamente verificáveis, o que distingue os espaços urbano e rural são as noções de pertencimento e identidade, os sistemas de valores e o imaginário compartilhado pelas populações. Estes conceitos instauraram questionamentos sobre o papel do homem do campo e suas tradições produtivas, no espaço rural. Antes visto como alguém isolado, de pouca instrução e importância social secundária, o homem do campo tornou-se o "jardineiro da natureza" (CARNEIRO, 2003, p. 7), alguém cuja presença no meio rural seria critério de qualidade e proteção ambiental. Essa nova identidade do homem do campo, provocada por uma mudança no imaginário das populações, gerou uma ruptura entre os conceitos de produção agrícola e manutenção ecoambiental.

A sociedade passou a demandar novas formas de ocupação do espaço rural, menos destrutivas da natureza e, ao mesmo tempo, pretendeu isolar os rincões ainda preservados da ação humana, a partir da adoção de reservas e parques ambientais. Para o agricultor, a ênfase das políticas públicas, agora, era a sua reinserção na paisagem rural, rejeitando o modelo desenvolvimentista agrícola. Aos poucos, o cerne da identidade do produtor agrícola foi se deslocando da esfera produtiva para o ambiente simbólico. A passagem do ambiente rural como núcleo de produção de bens materiais, para celeiro de bens simbólicos, avocou uma nova forma de organização produtiva. Conquanto o espaço rural não devesse ser descaracterizado para dar lugar à expansão do agronegócio, ele deveria se manter, até certo ponto, virgem, original, para que se tornasse objeto de contemplação. A nova organização produtiva, com base na contemplação, revitalizou, ou mesmo reinventou, uma cultura rural, cuja exploração é altamente rentável, seja na forma do agroturismo, do turismo étnico ou da comercialização dos produtos culturais do campo, tais como a música, a moda ou a culinária.

Neste ponto, os Kaimbé começaram a ser valorizados, sobretudo, porque se encaixavam, assim como os demais povos etnicamente diferenciados, no imaginário dos intelectuais baianos sobre o "jardineiro da natureza", ou seja, o homem primevo, integrado ao ambiente rural, ainda intocado ou pouco tocado. Os antropólogos acorreram ao município de Euclides da Cunha e à Serra do Massacará, munidos de todos os argumentos científicos possíveis, para legitimar a indianeidade dos Kaimbé. Assim, em 1992, o processo de demarcação do Território Indígena do Massacará foi finalizado e, em 1999, aconteceu a desintrusão dos não-indígenas que ainda viviam nas terras Kaimbé. Não coincidentemente, sob a égide da interpretação idealista-humanista da Sociologia Rural, as políticas públicas, 
propostas pelo Estado, para os povos etnicamente diferenciadas vieram de encontro à iniciativa de demarcar as terras e isolar as populações, porém sem que subsídios fossem ofertados para o seu pleno desenvolvimento.

Diante as duas interpretações promovidas pela Sociologia Rural, Carneiro (2003) optou por focar as questões da identidade e do imaginário, como fundadoras e mantenedoras da relação, e diferenciação, entre o rural e o urbano. Nas palavras da autora: "[...] consideramos mais proveitoso, em termos analíticos, orientarmos nossos esforços para buscar, a partir do olhar dos atores sociais, os significados das práticas sociais que tornam operacional esse tipo de interação (e distinção).[...]" (CARNEIRO, 2003, p. 14). Os tecidos da ruralidade e da urbanidade se deslocam, então, da materialidade observada no campo e na cidade, para o nível do imaginário das pessoas, de onde podem ser experienciados, independente do lugar em que o indivíduo se encontra: campo ou cidade. Note-se que não há dicotomia ou interpenetração, mas concomitância. Os Kaimbé, por exemplo, carregam o seu pertencimento e a sua aldeia no Massacará até a São Paulo urbana, para onde acorrem, em busca de trabalho.

A assunção de categorias subjetivas, idealizadas, de ruralidade e urbanidade, norteadoras de experiências e trocas simbólicas nos ambientes rural e urbano, promovem novos nichos de atuação, conflitos e contradições entre as populações, porque evocam aquilo que Bourdieu (1993) denominou "categoria social realizada", ou seja, uma perspectiva, política, ideológica e relacional, sobre a sociedade e sobre o lugar do próprio indivíduo nela. Dessa "categoria social realizada", brotariam as identidades e se sustentariam as reivindicações sociais. Carneiro (2003), então, arremata: "[...] Nesses termos, consideramos que a noção de rural corresponde a construções simbólicas pertencentes a diferentes universos culturais que lhes atribuem significados distintos. [...]" (CARNEIRO, 2003, p. 15). Esses significados orientam e incidem diretamente sobre a maneira como as populações e os indivíduos lidam com o ambiente rural. Sobre a natureza do rural como "categoria social realizada", Carneiro (2003) infere:

Nesse contexto, torna-se cada vez mais difícil pensar na noção de rural para qualificar um espaço ou a dinâmica das relações sociais num espaço. No entanto, essa dificuldade não nos parece estar presente na noção de localidade, já que esta não denota unicamente uma experiência espacial como definidora de um universo de relações sociais específicas. Em outros termos, a noção de localidade não define 
a natureza rural ou urbana de um grupo ou de suas práticas. (CARNEIRO, 2003, p. 18).

A autora (CARNEIRO, 2003) continua:

[...] a noção de localidade não se traduz simplesmente por um espaço fisicamente e socialmente ocupado. Ela seria útil justamente porque supõe um espaço que é tido, por aqueles que o ocupam, como uma referência e como uma base física de um conjunto de relações sociais diversificadas (de trocas, de sociabilidade, de solidariedade, de disputas e de conflitos) que dão sentido à existência de seus habitantes, isto é, lhes dão uma referência identitária. [...]. (CARNEIRO, 2003, p. 18).

Ao assumir essa perspectiva, a autora conduz a conceituação do rural e do urbano para os agentes do processo, as pessoas e os grupos sociais. No lugar de um espaço material, como base produtiva, o objeto de estudo é o espaço simbólico, advindo do imaginário e das noções fundamentais de pertencimento, mas com consequências obvias na maneira como os indivíduos ou grupos sociais se relacionam, com o lugar e entre si mesmos. A ruralidade estaria matizada na maneira como os habitantes do rural se identificam a si mesmos, perante os "não-rurais", independentemente do espaço material que ocupam, pois "[...] as fronteiras entre os territórios [rural e urbano] são, nesse sentido, móveis e podem até mesmo ser deslocadas de uma espacialidade física. [...]" (CARNEIRO, 2003, p. 20).

Quanto à identidade Kaimbé, entende-se que a sua indianeidade esteja situada no imaginário do grupo, como fundadora da relação entre o que é indígena e o que é nãoindígena. Do conflito pela legitimação, primeiro das terras, depois da própria indianeidade, brota a identidade Kaimbé, ligada ao seu território e mantida pela ressignificação do arsenal urbano, presente no cotidiano do grupo. A cosmovisão Kaimbé se reafirma nesse amalgama pós-moderno de referências e modos de viver.

\section{"Ruralidade urbana" Kaimbé: o avesso da questão}

Inseridos na lógica dos movimentos campesinos e constringidos por circunstâncias climáticas, políticas e socioeconômicas, que promoveram, historicamente, o êxodo das populações do semiárido baiano às capitais brasileiras, em especial para a cidade de São Paulo, os Kaimbé registram forte presença no cotidiano paulistano. Embora não haja estatísticas oficiais sobre o quantitativo de indivíduos Kaimbé que habitam São Paulo, e 
outras capitais brasileiras, é possível detectar, nos meios de comunicação e na internet, manifestações dessa etnia em solos alheios ${ }^{15}$.

Essa acintosa urbanização das populações indígenas aponta para dois fenômenos socioespaciais, iniciados no século XX: por um lado, houve forte migração indígena em direção às grandes cidades, movidos, sobretudo, pela busca de melhores condições de vida e trabalho, embora muitas populações indígenas tenham sido simplesmente expulsas das suas terras originais por latifundiários ou pelo próprio Poder Público. Por outro lado, muitas cidades cresceram desmesuradamente e terminaram por abarcar aldeias próximas de $\mathrm{si}^{16}$ (COMISSÃO PRÓ-ÍNDIO DE SÃO PAULO, 2013). De toda sorte, o processo de urbanização indígena é irreversível, portanto, ações afirmativas para a melhoria das condições de vida dos indígenas, habitantes das cidades, devem ser efetivamente implantadas, não apenas no sentido de prover-Ihes dignidade social, mas, também, oferecendo-lhes condições para o seu pleno desenvolvimento étnico, cultural e religioso.

Ao longo do século $X X$, a política indigenista esteve mais preocupada com 0 reconhecimento e a demarcação de terras indígenas, do que, especificamente, com as questões identitárias e socioculturais. O problema é que os temas territoriais perderam sentido, quando as populações indígenas migraram para os centros urbanos; ao passo que a identidade, o pertencimento e a herança cultural voltam a compor as demandas indígenas, com as quais o Estado deve lidar. A presença dos grupos indígenas nas cidades acrescenta, aos desafios naturais das políticas públicas indigenistas, os problemas oriundos do exercício do direito à cidade (COMISSÃO PRÓ-ÍNDIO DE SÃO PAULO, 2013).

Uma das grandes questões, que envolvem a assunção da identidade indígena, é a necessidade de sua subsistência no meio urbano. De acordo com Oliveira (1998), é necessário que se crie novas possibilidades de trabalho, que não obriguem os indígenas desterritorializados a abdicar da sua cultura e da sua identidade. De uma forma geral, as

\footnotetext{
${ }^{15}$ Cf. Documentário KAIMBÉ MASSACARÁ EM SÃO PAULO (2013).

${ }^{16}$ Os autores tomam, como exemplo, a cidade de São Paulo, que englobou três aldeias guaranis ao longo da sua expansão urbana, mas, no caso Kaimbé, pode ser citada a expansão da cidade de Euclides da Cunha, cujo desenvolvimento experimentado após a construção da ponte do Ibó, ligando Bahia e Pernambuco, pela BR 116, nos anos de 1990, fez com que a população exógena do município aumentasse, consideravelmente, sufocando as comunidades Kaimbé, que habitam fora do território do Massacará.
} 
populações indígenas que habitam cidades sobrevivem de confecção de artesanato, apresentações culturais e empregos sazonais.

Sousa (2010) ressalta que a educação de melhor qualidade consta entre os principais atrativos para o deslocamento das populações indígenas para as cidades. Aos indígenas, é garantido, por força de lei ${ }^{17}$, o acesso a uma educação diferenciada, bilíngue e intercultural. As escolas indígenas mantenedoras dessa proposta educativa, no entanto, são mais comuns nos territórios indígenas. Nas cidades, os estudantes indígenas terminam sendo matriculados em escolas comuns, o que pode ser desastroso para a construção da sua identidade indígena. Urge, também, superar o desafio de conciliar dois modelos pedagógicos, indígena e nãoindígena, nas instituições educativas que, em princípio, não são indígenas. Além disso, existe o problema do preconceito, que crianças e adolescentes indígenas enfrentam, nas escolas não-indígenas, especialmente, nos grandes centros urbanos.

O acesso aos serviços de saúde indígena, também, é mais difícil para os indígenas, que habitam os grandes centros urbanos, uma vez que as suas demandas específicas são escamoteadas, diante das exigências cotidianas dos demais usuários dos sistemas de saúde urbanos $^{18}$. Das capitais brasileiras, apenas São Paulo conseguiu implementar um Programa de Saúde da Família (PSF), voltado, especificamente, às populações indígenas (COMISSÃO PRÓ-ÍNDIO DE SÃO PAULO, 2013).

Diante de todas essas dificuldades, naturalmente, os indígenas que habitam os centros urbanos brasileiros se municiam de estratégias que garantam, tanto o conforto da sua sobrevivência material, quanto a manutenção da sua identidade. Uma estratégia que pode ser percebida entre os Kaimbé que vivem em São Paulo é a exibição ostensiva dos seus signos de identidade étnica ${ }^{19}$, dos seus saberes étnicos ${ }^{20}$ e das suas práticas espirituais ${ }^{21}$, afirmados, na cidade grande, como maneira de delimitar o estatuto da sua indianeidade, perante os não-indígenas. Isso, certamente, acarreta benefícios para as suas comunidades,

${ }^{17}$ Cf. BRASIL, Constituição Federal, Art. 210 (BRASIL, Constituição, 2011), e Lei de Diretrizes e Bases da Educação Nacional n 9.394, de 1996 (BRASIL, MEC, 1996).

${ }^{18}$ A partir de 1999, o Subsistema de Atenção à Saúde Indígena, componente do Sistema Único de Saúde (SUS), passou a prestar serviços aos grupos indígenas brasileiros. Com a extinção da FUNASA, em 2010, esses serviços passaram à responsabilidade da SESAI, ligada ao Ministério da Saúde (COMISSÃO PRÓ-ÍNDIO DE SÃO PAULO, 2013).

${ }^{19}$ Cocares, chocalhos, brincos etc.

${ }^{20}$ Lendas, remédios naturais, canções etc.

${ }^{21}$ Toré, novenas, rezas de olhado etc. 
seja pela proximidade com os grupos indigenistas que estão no mesmo território, seja pela visibilidade que a sua cultura assume, perante os meios de comunicação de massa, o que, por sua vez, pressiona o Estado a atender as suas demandas.

O fato é que pode ser detectada, nessa dinâmica, traços de uma "ruralidade urbana", ou seja, se o conceito de urbanidade rural aponta para a apropriação ressignificada do knowhow, próprio da cidade, pelo ambiente rural; o contrário também pode ser inferido, entre os Kaimbé, que moram em São Paulo: eles se (re)apropriam da sua própria cultura, resignificando-a, perante o ambiente urbano em que vivem. Essa ressiginificação cria novos produtos culturais que, em princípio, não são nem rurais, nem urbanos 22 .

Como o fluxo migratório dos Kaimbé não é unilateral, eventualmente, boa parte dos indivíduos retornam a Euclides da Cunha e à região do Massacará, levando consigo as suas reinterpretações culturais urbanas, sobre a cultura Kaimbé. Essas reinterpretações, obviamente, são bem-vindas aos processos dialéticos da elaboração cultural étnica, porquanto ventilam as suas características identitárias, promovendo a sobrevivência do seu manancial cultural. Por outro lado, em populações que são questionadas quanto à sua legitimidade étnica, como é o caso dos Kaimbé, as reintepretações parecem oferecer ainda mais munição aos seus depreciadores.

\section{Considerações finais}

Muito mais do que uma certidão, mais do que um quinhão de terra na Serra do Massacará, mais do que os traços fenotípicos, que podem ser de quaisquer cores ou compleições, o que define a identidade Kaimbé é sua indianeidade, manifestada no seu imaginário e na sua cosmovisão. Do conflito entre o ser Kaimbé e o não-ser Kaimbé, surgem as reinvenções de uma indianeidade que, se não pode ser originária, abraça, ao menos, uma indianeidade possível, entre veículos automotores, eletrodomésticos e aparelhos celulares. Estranhamente, esta é uma afirmação ainda necessária, em nome da legitimação de uma população acusada de usurpadora de um modelo étnico, que subsiste apenas no ideário das pessoas.

\footnotetext{
${ }^{22}$ Como, por exemplo, os painéis decorativos, feitos de palha de sisal, que são postos para alugar, por indígenas, para festas e eventos, na cidade de São Paulo.
} 
Mal superada a aceitação dos Kaimbé como indígenas Kaimbé, outro impasse derivado deste, em larga medida - é apresentado como ameaça ao pleno exercício da sua indianeidade: a carência de subsídios, na forma de políticas públicas, para o desenvolvimento dessa população, sobretudo, levando-se em conta a sua especificidade cultural. Se, nos últimos anos de governos sociais-democráticos, essas políticas não foram capazes de alcançar o êxito desejado, agora, com um governo claramente neoliberal e de tendências atávicas, elas praticamente deixam de existir.

Ainda que, em anos recentes, os povos indígenas tenham galgado significativos degraus em direção à autonomia e à gerência dos seus recursos, a realidade é que o tem feito quase à revelia do Estado. A despeito disso, contam com algum apoio das organizações nãogovernamentais (ONG), de segmentos da sociedade civil e das agências internacionais, essas, motivadas, especialmente, pela Resolução no 30 do Conselho da União Europeia (de 30 de novembro de 1998), que afirma o direito ao "[...] desfrute de seus próprios meios de subsistência e desenvolvimento e de dedicar-se livremente a todas as suas atividades econômicas, tradicionais e de outro tipo" (ONU, 2015, p 12).

O contato entre os Kaimbé e sociedade do seu entorno trouxe mudanças importantes para a comunidade da Serra do Massacará. Essas mudanças impactaram o modo de viver Kaimbé, no seu cotidiano e na produção da sua sobrevivência, o que implicou a transposição de práticas urbanas para os ambientes do território indígena Kaimbé, constituindo o fenômeno da "urbanidade rural". Como estratégia de sobrevivência cultural, essas práticas foram ressignificadas, em favor dos costumes, próprios da identidade étnica e territorial Kaimbé.

É importante ressaltar que as práticas urbanas, trazidas ao Território Indígena do Massacará, chegam por meio do contato imediato dos Kaimbé com a sociedade de entorno, mas, também, pelas reelaborações dos indivíduos da comunidade, que migram para as grandes cidades e, posteriormente, retornam à sua localidade, com transformações evidentes nas manifestações da sua indianeidade. Tais transformações avocam uma "ruralidade urbana", uma reapropriação da sua própria cultura, perante o ambiente urbano em que viveram. Em ambos os movimentos - urbanidade rural e ruralidade urbana - a identidade Kaimbé se afirma e transcende, assumindo contornos que tornam a sua indianeidade apta ao futuro. 


\section{Referências}

APPADURAI, Arjun. Fear of small numbers: an essay on the geography of anger. Durham: Duke University Press, 2006.

AZANHA, Gilberto. 2002. Etnodesenvolvimento, mercado e mecanismos de fomento: possibilidades de desenvolvimento sustentado para as sociedades indígenas no Brasil. In LIMA, Antônio Carlos de Souza; BARROSO-HOFFMANN, Maria (org.):

Etnodesenvolvimento e Políticas Públicas: bases para uma Nova Política Indigenista. Rio de Janeiro: ContraCapa, 2002. p. 29-37

BATISTA, Hildonice de Souza. Memórias indígenas: novos valores para uma educação etnorracial. GEPIADDE, Itabaiana, n. 10, p. 28-43, jul./dez., 2011.

BOURDIEU, Pierre. A propos de la famille comme catégorie réalisée. Actes de la Recherche en Sciences Sociales. Paris-FR, EHESS, n. 100, p. 32-36, dez., 1993.

BRASIL, Ministério da Educação - MEC. Lei n 9.394, de 20 de dezembro de 1996.

Estabelece as diretrizes e bases da educação nacional. 1996. Disponível em: http://portal.mec.gov.br/seed/arquivos/pdf/tvescola/leis/leing394.pdf. Acesso em: 2 jan. 2018.

BRASIL, Ministério Público Federal - MPF. Ação civil pública com pedido de decisão liminar em desfavor da FUNAI - Fundação Nacional do Índio. Paulo Afonso: Mimeo, 2013 .

BRASIL, Presidência da República, Casa Civil. Constituição da República Federativa do Brasil: promulgada em 5 de outubro de 1988. São Paulo: Atlas, 2011. 126 p.

CANTON, Anayme Aparecida. A escola como espaço de afirmação da identidade Kaimbé: o recorte feminino. Revista Olhares Docentes. Euclides da Cunha, v. 2, n. 2, p. 124-145, jun./dez., 2018.

CARNEIRO, Maria José. Ruralidade na sociedade contemporânea: uma discussão teóricometodológica. In: EL MUNDO RURAL: transformaciones y perspectivas a la luz de la nueva ruralidad. Bogotá-BV: Pontifícia Universidad Javeriana, 2003. CD-Rom

CARVALHO, Maria Lucia Brant de. Saúde de populações indígenas: tendências após os impactos do contato. São Paulo, 1997, 190 f. Dissertação (Mestrado em Ciências Sociais). Pontifícia Universidade Católica de São Paulo, São Paulo, 1997.

COMISSÃO PRÓ-ÍNDIO DE SÃO PAULO. A cidade como local de afirmação dos direitos indígenas. São Paulo: Centro Gaspar Garcia de Direitos Humanos, 2013.

FARIA, Ivani Ferreira de. Território e territorialidades indígenas do Alto Rio Negro. Manaus: Editora da UFAM, 2003.

FORNO, Marlise Amália Reinehr Dal; VERDUM, Roberto; KUBO, Rui Regina. Riscos e conflitos ambientais na perspectiva da conservação da natureza e das identidades sociais. 
In: SOUZA, Gabriela Coelho de (org.). Transformações no espaço rural. Porto Alegre: EdUFRS, 2010. p. 9-24

GRÜNEWALD, Rodrigo de Azeredo. Etnodesenvolvimento indígena no Nordeste (e Leste): aspectos gerais e específicos. Revista Anthropológicas. Recife, n. 14, p. 47-71, 2003.

KAIMBÉ MASSACARÁ EM SÃO PAULO. Documentário. Trabalho de Conclusão de Curso em comunicação social, habilitação em Jornalismo, apresentado à Faculdade Paulus de Tecnologia e Comunicação, FAPCOM. 2013. Disponível em:

https://www.youtube.com/watch?v=l97XgZfNKbQ\&t=13s. Acesso em: 13 out. 2018.

LINDOSO, Dirceu. Lições de etnologia geral: introdução ao estudo dos seus princípios, seguido de dois estudos de etnologia brasileira. Maceió: EDUFAL, 2008.

MEADER, Robert E. Índios do Nordeste: levantamento sobre os remanescentes tribais do Nordeste brasileiro. Cuiabá: SLI, 1976.

MOQUAY, Patrick. L'invention dês nouveaux territoires: une urbanité rurale. In: DEFFONTAINES, Jean-Pierre; PROD'HOME, Jean-Pierre (org.). Territories et acteurs du développemente local: de nouveaux liex de démocratie. La Tour-d'Aigues-FR: Éditions de L'aube, 2001. p. 133-141.

MOQUAY, Patrick. Les territoires de chartes: autour de l'ouvrage Essai sur l'urbanité rurale. Actes de la journée d'étude, développement territorial recherches et débats. Paris, $\mathrm{n}^{\circ} \mathrm{O}$, 49-57 p., maio, 1998.

NASH, Dennison. Anthropology of tourism. Kidlington: Pergamon Press, 1996.

OLIVEIRA, João Pacheco de. A viagem de volta: etnicidade, política e reelaboração cultural no nordeste indígena. Rio de Janeiro: Contra Capa, 1999.

OLIVEIRA, João Pacheco de. Uma etnologia dos "índios misturados"? Situação colonial, territorialização e fluxos culturais. Conferência realizada no concurso para professor-titular da disciplina Etnologia, Museu Nacional/UFRJ, Rio de Janeiro, 11 de novembro de 1997. MANA 4, 1, n. 1, p. 47-77, 1998.

OLIVEIRA, João Pacheco de (org.). A presença indígena no Nordeste: processos de territorialização, modos de reconhecimento e regimes de memória. Rio de Janeiro: Contra Capa, 2011.

ONU - Organização das Nações Unidas; CMMAD - Comissão Mundial sobre Meio Ambiente e Desenvolvimento. Nosso futuro comum. Rio de Janeiro: Fundação Getúlio Vargas, 1988. $374 \mathrm{p}$.

ONU, Organização das Nações Unidas; CEPAL, Comissão Econômica para a América Latina e o Caribe. Os Povos Indígenas na América Latina: avanços na última década e desafios pendentes para a garantia de seus direitos. Santiago-Chile: CEPAL, 2015.

REESINK, Edwin Boudewijn. Olhos miúdos e olhos graúdos em Massacará: a ideologia étnica. Revista Anthropológicas. Recife, ano 21, v. 28, n. 2, p. 6-26, 2017. 
REESINK, Edwin Boudewijn. A Questão do Território dos Kaimbé de Massacará: um levantamento histórico". Gente - Revista do Depto de Antropologia-FFCH/UFBA. Salvador, v. 1, n. 1, p. 125-137, jun./dez., 1984.

REESINK, Edwin Boudewijn. Índio ou caboclo: notas sobre a identidade étnica dos índios do Nordeste. Salvador: Universitas, 1983.

REESINK, Edwin Boudewijn; MCCALLUM, Cecília; RESTREPO, Eduardo. Apresentação do Dossiê Racismo no Plural nas Américas: povos indígenas e afro-indígenas. Revista Anthropológicas. Recife, Ano 21, v. 28, n. 2, p. 1-5, 2017.

SOUSA, Cássio Noronha Inglez de (org.) et al. Povos indígenas: projetos e desenvolvimento II. Brasília: Paralelo 15, 2010.

SOUSA, Rainer. De araque. Brasil Escola. Disponível em: https://brasilescola.uol.com.br/curiosidades/de-araque.htm Acesso em: 24 jun., 2018.

SOUZA, Bruno Sales de. Fazendo a diferença: um estudo da etnicidade entre os Kaimbé do Massacará. Salvador, 1996a, 164 f. Dissertação (Mestrado em Sociologia). Faculdade de Filosofia e Ciências Humanas, Universidade Federal da Bahia, Salvador, 1996a.

SOUZA, Marcelo Lopes de. Teorização sobre o desenvolvimento em uma época de fadiga teórica, ou: sobre a necessidade de uma "teoria aberta" do desenvolvimento sócio-espacial. Revista Território. Rio de Janeiro, v. 1, n. 1, 1996b.

STAVENHAGEN, Rodolfo. Etnodesenvolvimento: uma dimensão ignorada no pensamento desenvolvimentista. In: ANUÁRIO ANTROPOLÓGICO. Rio de Janeiro: Tempo Brasileiro, 1984. 11-44 P.

TOLEDO, Renata Ferraz de; GIATTI, Leandro Luiz; PELICIONI, Maria Cecília Focesi. Urbanidade rural, território e sustentabilidade: relações de contato em uma comunidade indígena no noroeste amazônico. Ambiente \& Sociedade. Campinas, v. 12, n. 1, p. 173-188, jan./jun., 2008.

\section{Detalhes do autor}

Alfons Heinrich Altmicks

Mestre em Ciências da Educação (USCar). Mestre em Planejamento Territorial e Desenvolvimento Social (UCSal). Doutorando em Educação e Contemporaneidade (PPGEDuc-UNEB). Docente integrante dos quadros da Universidade Católica do Salvador. E-mail: alfons.altmicks@pro.ucsal.br 